\title{
Serum levels of miR-320 family members are associated with clinical parameters and diagnosis in prostate cancer patients
}

\author{
Verena Lieb ${ }^{1}$, Katrin Weigelt ${ }^{1}$, Lena Scheinost ${ }^{1}$, Kersten Fischer ${ }^{2}$, Thomas Greither ${ }^{3}$, \\ Marios Marcou ${ }^{2,3}$, Gerit Theil ${ }^{2}$, Helmut Klocker ${ }^{4}$, Hans-Juergen Holzhausen ${ }^{5}$, \\ Xin Lai ${ }^{6}$, Julio Vera ${ }^{6}$, Arif B. Ekici', Wolfgang Horninger ${ }^{4}$, Paolo Fornara ${ }^{2}$, Bernd \\ Wullich ${ }^{1}$, Helge Taubert ${ }^{1}$ and Sven Wach ${ }^{1}$
}

\footnotetext{
${ }^{1}$ Department of Urology and Pediatric Urology, Universitätsklinikum Erlangen, Friedrich-Alexander-Universität ErlangenNürnberg, Erlangen, Germany

${ }^{2}$ Department of Urology, Martin-Luther-University Halle-Wittenberg, Halle, Germany

${ }^{3}$ Center for Reproductive Medicine and Andrology, Martin-Luther-University Halle-Wittenberg, Halle, Germany

${ }^{4}$ Department of Urology, Medical University Innsbruck, Innsbruck, Austria

${ }^{5}$ Institute of Pathology, Martin Luther University Halle-Wittenberg, Halle, Germany

${ }^{6}$ Laboratory of Systems Tumor Immunology, Department of Dermatology, Universitätsklinikum Erlangen, Friedrich-AlexanderUniversität Erlangen-Nürnberg, Erlangen, Germany

${ }^{7}$ Institute of Human Genetics, Friedrich-Alexander-Universität Erlangen-Nürnberg, Erlangen, Germany

Correspondence to: Helge Taubert, email: helge.taubert@uk-erlangen.de

Keywords: miR-320 family; diagnosis; prostate cancer; PSA

Abbreviations: PCa: prostate cancer; PSA: prostate specific antigen; OS: overall survival; RPE: radical prostatectomy; BPH: benign prostatic hyperplasia.

Received: July 06, $2017 \quad$ Accepted: December 23, $2017 \quad$ Published: December 30, 2017

Copyright: Lieb et al. This is an open-access article distributed under the terms of the Creative Commons Attribution License 3.0 (CC BY 3.0), which permits unrestricted use, distribution, and reproduction in any medium, provided the original author and source are credited.
}

\section{ABSTRACT}

We studied the association of the serum levels of the microRNA family members miR-320a/-b/-c with clinico-pathological data to assess their applicability as diagnostic biomarker in prostate cancer ( $P C a$ ) patients. The levels of miR-320a/b/-c in 3 groups were evaluated by qRT-PCR (145 patients with PCa, 31 patients with benign prostatic hyperplasia (BPH) and 19 healthy controls). The levels of the three family members of miR-320 were directly correlated within each group $(P<$ $0.001)$, but they differed significantly among the three groups $(P<0.001)$. The serum levels of the miR-320 family members were significantly increased in older patients compared to younger patients ( $\leq 66$ years vs. $>66$ years, $P \leq 0.001$ ). In addition, the levels of all three miR-320 family members were significantly different in patients with low tumor stage compared with those with high tumor stage (miR-320a: $P=$ 0.034; miR-320b: $P=0.006$; miR-320c: $P=0.007$ ) and in patients with low serum PSA compared with those with high serum PSA ( $\leq 4 \mathrm{ng}$ vs. $>4$ ng; miR-320a: $P=$ 0.003; miR-320b: $P=0.003$; miR-320c: $P=0.006$ ). The levels of these miRNAs were inversely correlated with serum PSA levels. Detection in the serum samples of PCa patients with or without PSA relapse revealed higher levels of miR-320a/-b/-c in the group without PSA relapse before/after radical prostatectomy than in that with PCa relapse.

In summary, the differences among the $\mathrm{PCa} / \mathrm{BPH} /$ healthy control groups with respect to miR-320a/-b/-c levels in conjunction with higher levels in patients without a PSA relapse than in those with a relapse suggest the diagnostic potential of these miRNA-320 family members in PCa patients. 


\section{INTRODUCTION}

The microRNA miR-320 family is conserved, but only exists in vertebrates from Xenopus to humans. This miRNA family consists of five members: miR-320a, -b, -c, -d and -e (miR-320d/-e present only in primates and humans; Targetscan: http://www.targetscan.org/cgi-bin/targetscan/ vert_71/mirna families.cgi? $\mathrm{db}=$ vert_ $71 \&$ species $=$ Human).

In the literature, the general term miR-320 is used most frequently, but when a sequence is given, it is predominantly that of miR-320a. miR-320 has been shown to regulate physiological processes such as cardiac survival (apoptosis) [1] and glucose-induced gene expression in diabetes [2], but most studies have investigated different tumor entities. miR-320 is downregulated in different tumors compared with normal/non-tumor tissue, such as in breast cancer [3-5], mesothelioma [6], liver cancer both in hepatic cholangiocarcinoma [7] and in hepatocellular carcinoma [8], lung cancer both in NSCLC [9] and SCLC [10], colon and colorectal cancer [11, 12], prostate cancer [13-15], oral cancer [16], and cervical cancer [17]. However, one report describes a 4-fold upregulation of miR-320 in neuroblastoma compared with normal retinal tissue [18]. The diagnostic utility of decreased miR-320 in the peripheral blood of glioblastoma patients compared with healthy probands has also been shown [19]. The downregulation of this miRNA was further associated with more aggressive behavior and/or poor prognosis in SCLC [10], colon cancer [11], breast cancer [3, 4], and cervical cancer [17]. Recently, an association between reduced miR-320a transcript levels in tumor tissue and a poor overall survival for prostate cancer patients was reported [15]. Taken together, this evidence not only shows the involvement of the miR-320 family in cancer development and progression, it also suggests the potential use of this microRNA family in clinical practice. However, an association of miR-320 family members with clinicopathological data and their utility as diagnostic serum markers have not yet been studied in prostate cancer patients comprehensively.

\section{RESULTS}

\section{General characteristics and expression levels of miR-320a, -b, and -c}

The microRNA 320 family consists of five members (miR-320a-e). The members miR-320a, -b and -c showed detectable levels in the miRNA microarray but miR-320d and -e did not. Therefore, we excluded miR-320d and -e from further studies. The miR-320a gene is located on chromosome 8 , whereas the miR-320b1/-2 genes are located on chromosome 1 and the miR-320c1/-2 genes are located on chromosome 18; however, the genes are expressed as one (miR-320a) or two transcripts (miR- 320b1/-b2 and -c1/-c2). For all three miRNAs (miR-320a, $-b,-c)$, the $3^{\prime}$ strand is predominantly expressed. The mature miRNAs have the following sequences (miRBase: http://www.mirbase.org/):

hsa-miR-320a-3p: 48 - aaaagcuggguugagagggega - 69 hsa-miR-320b-3p: 39 - aaaagcuggguugagagggcaa - 60 hsa-miR-320c-3p: 50 - aaaagcuggguugagagggu - 69

(seed sequence is marked in red, and divergent nucleotides are marked in blue).

The expression levels (range, mean and median) of the three miRNAs miR-320a, -b and -c that were measured in the serum of 145 patients with $\mathrm{PCa}, 31$ patients with $\mathrm{BPH}$ and 19 healthy donors are given in Table 1. The expression levels of all three miRNAs were highly correlated with each other in the serum samples of each of the three study groups (i.e., the PCa patients, the BPH patients and the healthy donors) (all $P<0.001$; Spearman's rank correlation test; Table 2). However, the levels differed significantly between patients with $\mathrm{PCa}$ and those with $\mathrm{BPH}$, and between both patient groups and the healthy controls (all $P<0.005$; Mann-Whitney $U$-test and Kruskal Wallis test; Table 1; Supplementary Figure 1). Interestingly, the healthy control group showed the lowest median levels of these miRNAs in the serum, followed by the PCa group; finally, the BPH group showed the highest median expression levels of these miRNAs. ROC analyses revealed a distinction between patients with $\mathrm{PCa}$ and those with BPH (miR-320a: AUC of 0.775; miR-320b: AUC of 0.850 and miR-320c: AUC of 0.751), between patients with PCa and healthy controls (miR-320a: AUC of 0.894 ; miR320b: AUC of 0.714 and miR-320c: AUC of 0.840) and between patients with BPH and healthy controls. However, the relatively low number of healthy controls must be considered (miR-320a: AUC of 0.997; miR-320b: AUC of 0.991 and miR-320c: AUC of 0.895; all with $P<0.005$; Figure 1).

\section{Correlation of miR-320 levels with clinico- pathological data}

The serum level of all three miR-320 family members was not equally distributed when PCa patients were separated by median age ( $\leq 66$ years vs. $>66$ years) according to their age at diagnosis $(P<0.001$; MannWhitney $U$-test). After the levels of miR-320a, -b, and $-c$ were separated by quartile, the lowest level (1st quartile) was found predominantly in the younger patient group while the highest level (4th quartile) was found predominantly in the elder patient group (miR-320a: $P=$ 0.001 ; miR-320b and -c: $P<0.001$; Fisher's exact test). However, after the classification of the BPH patients $(\leq 70$ years vs. $>70$ years) and the healthy controls ( $\leq 45$ years vs. $>45$ years) according to median age, no differences were observed in the levels of all three miR-320 family members between the age groups. 
Table 1: Serum levels of miR-320a, -b, -c in PCa patients, BPH patients and healthy controls

\begin{tabular}{|c|c|c|c|c|c|c|}
\hline & PCa & BPH & $\begin{array}{l}\text { healthy } \\
\text { controls }\end{array}$ & $\begin{array}{c}\text { PCa vs. BPH } \\
\mathbf{P}^{1}\end{array}$ & $\begin{array}{c}\text { PCa vs. healthy } \\
\text { controls } \\
\mathbf{P}^{1}\end{array}$ & $\begin{array}{c}\text { BPH vs. healthy } \\
\text { controls } \\
\mathbf{P}^{1}\end{array}$ \\
\hline$m i R-320 a$ & & & & $<0.001$ & $<0.001$ & $<0.001$ \\
\hline$n$ & 145 & 31 & 19 & & & \\
\hline range & $0.26-56.31$ & $1.27-13.55$ & $0.43-1.62$ & & & \\
\hline mean & 3.0666 & 4.9884 & 0.8566 & & & \\
\hline median & 2.2388 & 3.7890 & 0.8542 & & & \\
\hline $25 \%$ quartile & 1.2005 & 3.0574 & 0.6515 & & & \\
\hline $75 \%$ quartile & 3.7975 & 5.9952 & 0.9836 & & & \\
\hline$m i R-320 b$ & & & & $<0.001$ & 0.003 & $<0.001$ \\
\hline$n$ & 139 & 36 & 19 & & & \\
\hline range & $0.42-219.79$ & $1.97-41.36$ & $0.82-2.75$ & & & \\
\hline mean & 5.7385 & 13.0849 & 1.7648 & & & \\
\hline median & 2.9214 & 8.6052 & 1.8536 & & & \\
\hline $25 \%$ quartile & 1.4378 & 6.5050 & 1.3307 & & & \\
\hline $75 \%$ quartile & 5.4572 & 18.1321 & 1.8536 & & & \\
\hline$m i R-320 c$ & & & & $<0.001$ & $<0.001$ & $<0.001$ \\
\hline$n$ & 145 & 36 & 19 & & & \\
\hline range & $0.35-167.90$ & $1.17-13.62$ & $0.25-19.91$ & & & \\
\hline mean & 3.6962 & 4.6928 & 2.4067 & & & \\
\hline median & 2.0204 & 3.9124 & 0.5215 & & & \\
\hline $25 \%$ quartile & 0.8866 & 2.7534 & 0.3171 & & & \\
\hline $75 \%$ quartile & 3.6765 & 3.9124 & 0.5215 & & & \\
\hline
\end{tabular}

${ }^{1}$ Mann-Whitney $U$-test; The Bonferroni-adjusted threshold for significance is set at $\alpha=0.005$.

In addition, the levels of all three miR-320 family members were not equally distributed between the two tumor stage groups (pT1 + pT2 vs. pT3 + pT4) (miR320a: $P=0.034$; miR-320b: $P=0.032$ and miR-320c: $P=0.007$; Mann-Whitney $U$-test). After the expression levels were stratified according to quartile, only miR320 a showed a significant association with a higher serum level ( $3^{\text {rd }}$ and 4 th quartiles) and a higher tumor stage $(P=$ $0.017)$. However, miR-320b and -c showed only a trend of significance for this association $(P=0.075$ and $P=0.051$; Fisher's exact test).

A different distribution of miR-320 family member levels was also seen in the two PSA groups (PSA level $\leq$ 4 ng vs. PSA level $>4 \mathrm{ng}$ ) (miR-320a: $P=0.003$; miR320b: $P=0.004$ and miR-320c: $P=0.006$; Mann-Whitney $U$-test). Interestingly, we found an indirect association between the serum levels of miR-320a/-b/-c and the serum levels of PSA. That is, low miR-320 levels (1st and 2nd quartiles) were associated with higher PSA levels and high miR-320 levels (3rd and 4th quartiles) were associated with lower PSA levels (miR-320a: $P=0.003$; miR-320b: $P=0.006$; and miR-320c: $P<0.001$; Fisher's exact test).

\section{Early detection of $\mathrm{PCa}$ recurrence}

The detection of $\mathrm{PCa}$ recurrence (biochemical recurrence) is based on an increase in PSA levels (PSA relapse). Our finding of an indirect correlation between PSA expression and miR-320a, - b, and -c expression poses the question of if and how the serum levels of miR-320 family members might be associated with PCa recurrence. At first we investigated the PCa Halle cohort; for 77 patients (36 without and 41 with PSA relapse) the PSA relapse status was known. Comparison of miR$320 \mathrm{a},-\mathrm{b}$ and -c serum levels before and after radical prostatectomy (RPE) in the two PCa patient groups (without/with PSA relapse) revealed a significant increase in miR-320a, -b and -c levels between samples before and after RPE for the patients without PSA relapse (miR320a: $P=0.019$; miR-320b: $P=0.037$ and miR-320c: $P$ $=0.017$ ) but not for the patients with PSA relapse (mir320a: $P=0.177$; miR-320b: $P=0.648$; miR-320c: $P=$ 0.089; all Mann Whitney $U$-test; Figure 2). Next, at using a microRNA microarray we studied serum samples from two patient groups (i.e., with and without PSA recurrence; 
Table 2: Bivariate correlations among the serum levels of miR-320a, -b, and -c in PCa patients, BPH patients and healthy controls

\begin{tabular}{|c|c|c|c|c|c|}
\hline \multicolumn{6}{|c|}{ correlations } \\
\hline PCa patients & & & miR-320a & miR-320b & miR-320c \\
\hline \multirow[t]{6}{*}{ Spearman-Rho } & miR_320a & correlation coefficient & 1.000 & $.893^{* *}$ & $.937^{* *}$ \\
\hline & & Sig. (2-sided) & & .000 & .000 \\
\hline & & $\mathrm{N}$ & & 138 & 145 \\
\hline & miR_320b & correlation coefficient & & 1.000 & $.876^{* *}$ \\
\hline & & Sig. (2-sided) & & & .000 \\
\hline & & $\mathrm{N}$ & & & 138 \\
\hline BPH patients & & & miR-320a & miR-320b & miR-320c \\
\hline \multirow[t]{6}{*}{ Spearman-Rho } & miR_320a & correlation coefficient & 1.000 & $.858^{* *}$ & $.926^{* *}$ \\
\hline & & Sig. (2-sided) & & .000 & .000 \\
\hline & & $\mathrm{N}$ & & 31 & 31 \\
\hline & miR_320b & correlation coefficient & & 1.000 & $.856^{* *}$ \\
\hline & & Sig. (2-sided) & & & .000 \\
\hline & & $\mathrm{N}$ & & & 31 \\
\hline healthy controls & & & miR-320a & miR-320b & miR-320c \\
\hline \multirow[t]{6}{*}{ Spearman-Rho } & miR_320a & correlation coefficient & 1.000 & $.818^{* *}$ & $.930^{* *}$ \\
\hline & & Sig. (2-sided) & & .000 & .000 \\
\hline & & $\mathrm{N}$ & & 19 & 19 \\
\hline & miR_320b & correlation coefficient & & 1.000 & $.786^{* *}$ \\
\hline & & Sig. (2-sided) & & & .000 \\
\hline & & $\mathrm{N}$ & & & 19 \\
\hline
\end{tabular}

${ }^{* *}$ The correlation is significant at the 0.001 level (2-sided).

$N=4$ and 5, respectively) from the PCa Innsbruck cohort. In the group of PCa patients without recurrence, relatively high miR-320a/-b/-c levels were measured in serum samples obtained 5 years and 1 year before prostate cancer diagnosis. The levels were decreased in the serum collected at the time of diagnosis. Three months after RPE surgery and beyond, high miR-320a/-b/-c levels similar to those observed prior to surgery were again observed in the serum (Figures 3, 4). In the group of PCa patients with relapse, miRNA microarray analysis showed comparably lower levels of miR-320a/-b/-c in addition to a decrease in miR-320b (but not in miR-320a/-c) at diagnosis (Figures 3, 4). After RPE, the miR-320b levels increased to levels that were present before RPE, but this increase was less than that observed in the group without PSA relapse.

\section{Model to detect PCa recurrence}

To calculate sensitivity and specificity for prediction of $\mathrm{PCa}$ recurrence after radical prostatectomy, we developed a generalized linar logistic regression model with clinico-pathological and molecular parameters. At first we integrated clinico-morphological parameters known to affect PCa recurrence, i.e., PSA level, Gleason sum, tumor stage, age and resection margins (R0 vs. R1) in our base line model and obtained a sensitivity of $77.8 \%$ and a specificity of $75.0 \%$ to separate $\mathrm{PCa}$ without from those with recurrence. At including miR-320a,-b,-c levels in addition, a sensitivity of $82.3 \%$ and a specificity of $77.8 \%$ is calculated. In the literature the level of miR141 in serum/plasma has been described as relevant to distinguish between PCa without and with biochemical recurrence [20, 21]. Therefore, we analysed miR-141 level in our Halle cohort and added them to the previous model (PSA, Gleason sum, tumor stage, age and resection margins and miR-320a,-b,-c). A sensitivity of $93.7 \%$ and a specificity of $90.0 \%$ to distinguish between cases without/with PCa recurrence were achieved, suggesting that a model including clinico-pathological and several miRNA levels has an improved accuracy in the prediction of patients with $\mathrm{PCa}$ recurrence. 


\section{Association of miR-320a, -b, and -c levels with prognosis}

For the survival analysis, we separated the expression levels of miR-320a/-b/-c according to the quartiles. Interestingly, compared with intermediate expression levels (2nd and 3rd quartiles), the lowest and highest expression levels (1st and 4th quartiles) were associated with a poorer overall survival, although this difference was not statistically significant (data not shown). Therefore, we combined the 1 st +4 th quartiles (group 1) and the 2nd + 3rd quartiles (group 2). Considering the association of miR-320a/-b and -c levels with age, patients were also stratified into two age groups ( $\leq 66$ years vs. $>66$ years). In terms of miR-320b expression, group 1 patients (1st +4 th quartiles) of the younger patient group ( $\leq 66$ years) showed a significantly poorer OS than patients in group 2 (2nd +3 rd quartiles) $(P=0.034$; log- rank test). Moreover, group 1 patients died 30 months earlier than group 2 patients (119 vs. 149 months, Kaplan-Meier analysis; Figure 5) and had a 4.2fold increased risk of death (statistically insignificant $P=0.12$; multivariate Cox's regression hazard analysis, adjusted for PSA level and pT). A comparable effect was observed as trend for miR-320a levels $(P=0.053$, log-rank test), as patients in group 1 had a 2.8 -fold increased risk of death (statistically insignificant, $P=0.14$; multivariate Cox's regression hazard analysis, adjusted for PSA level
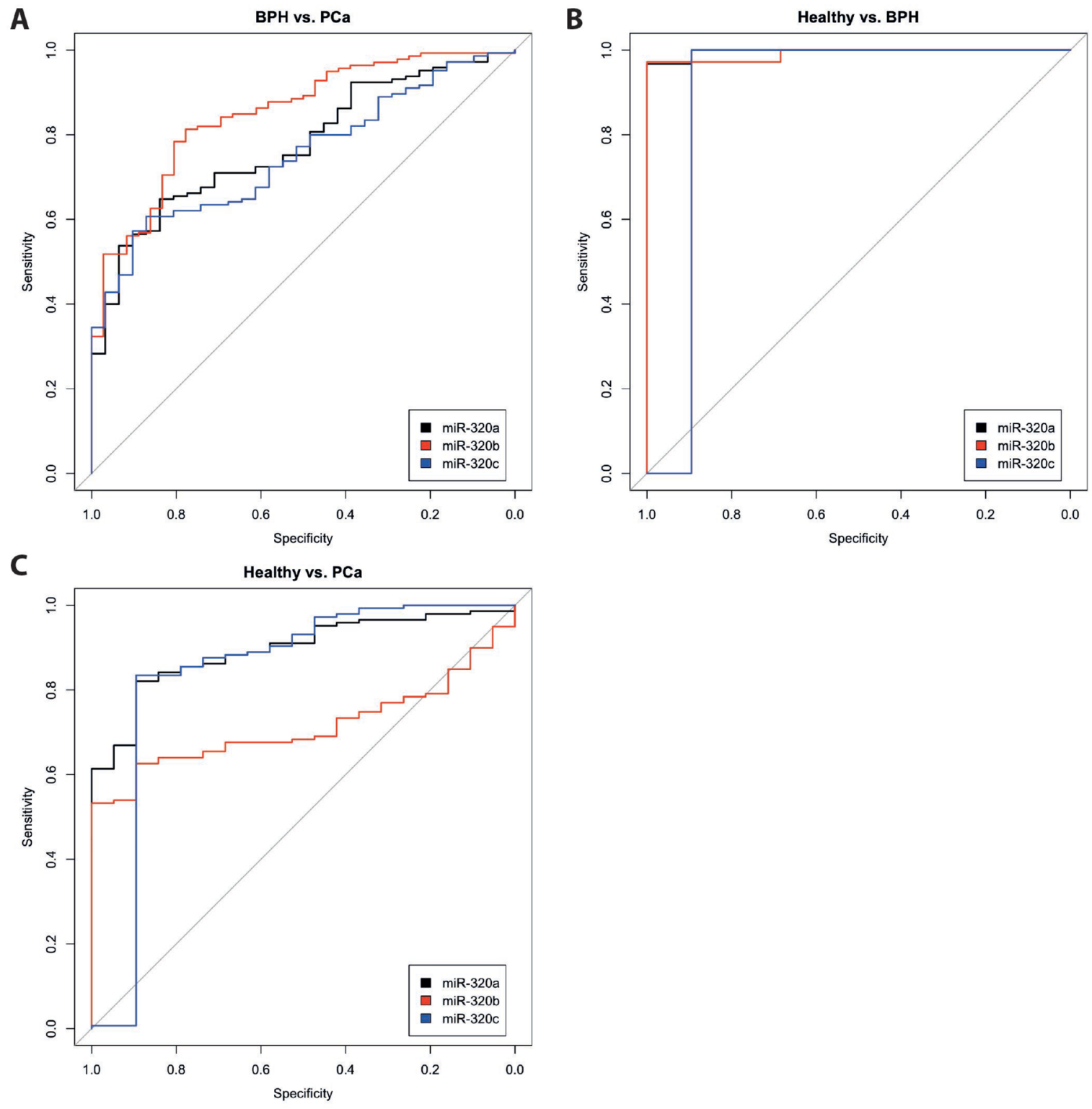

Figure 1: ROC analyses for miR-320 a, -b, and $\mathrm{c}$ in the serum of patients with PCa, patients with BPH and healthy controls. The miRNA levels of miR-320a (black), miR-320b (red) and miR-320c (blue) were compared between the groups PCa vs. BPH (A), Healthy controls vs. BPH (B) and Healthy controls vs. PCa (C). 
A

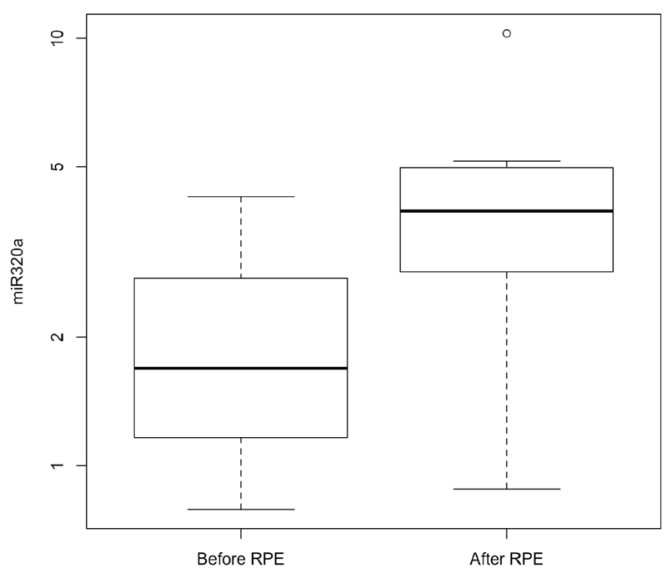

C

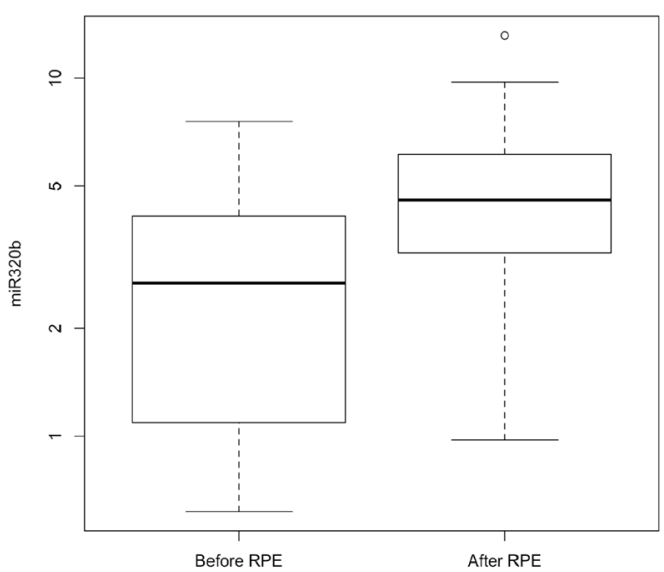

E

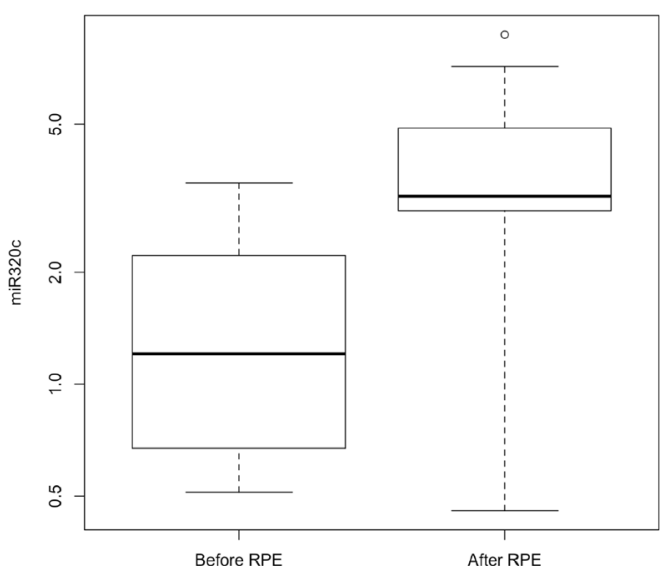

B

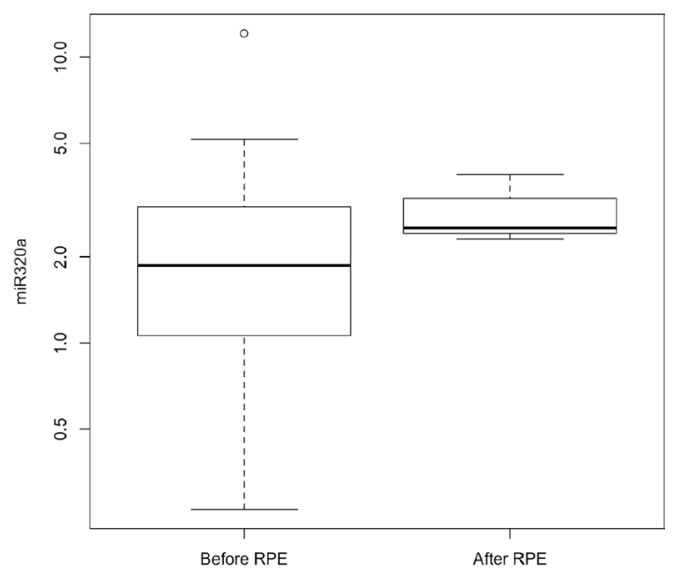

D

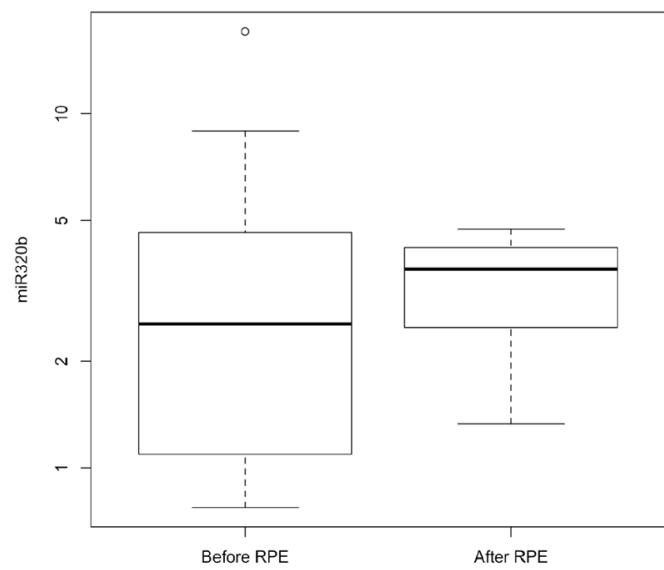

$\mathbf{F}$

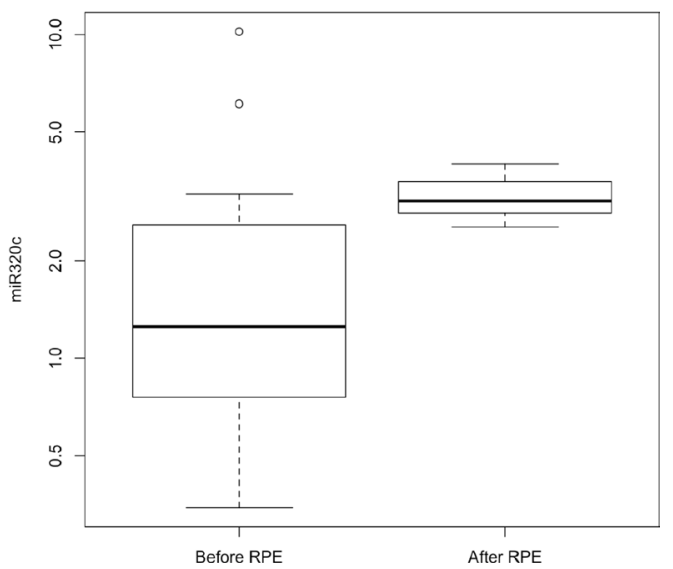

Figure 2: Comparison of miR-320a,-b and -c serum levels for PCa patients without/with PSA relapse before and after radical prostatectomy (Halle cohort). A comparison of miR-320a, -b and -c serum levels for PCa patients without ( $N=36$; $\mathbf{A}$, C, E) and with PSA relapse $(N=41 ; \mathbf{B}, \mathbf{D}, \mathbf{F})$ before and after radical prostatectomy. There was a significant increase in miR-320a, -b and -c levels between samples before RPE and after RPE for the patients without PSA relapse (miR-320a: $P=0.019 ;$ miR-320b: $P=0.037$ and miR-320c: $P=0.017$ ) but not for the patients with PSA relapse (mir-320a: $P=0.177$; miR-320b: $P=0.648$; miR-320c: $P=0.089$; all Mann Whitney $U$-test). Serum samples before and after the RPE originate from different PCa patients. 
and pT; data not shown). In contrast, no association was observed between the levels of these miRNAs and overall survival in the elder patient group.

\section{In silico prediction of miR-320a, -b, and -c target genes}

Next, we were interested in the target genes of miR-320a, -b and -c as well as their overlap. First, we used the miRTarBase database to extract experimentally verified target genes of the three miRNAs, and based on the technologies used to verify miRNA-gene interactions, these targets were categorized into two groups, as follows: strong and weak confidence groups. Interactions in the former group were verified by experiments such as qPCR, western blot and reporter assays, while interactions in the latter group were verified by high-throughput experiments, such as microarray, RNA sequencing and pSILAC. When we consider only the methods with strong evidence, 20 target genes were reported for miR-320a, none for miR$320 \mathrm{~b}$ and two for miR-320c (Supplementary Tables 1 and 2). Second, the database miRwalk2.0 was used to extract putative miRNA target genes that are predicted by 5 different algorithms (see Materials and Methods). In this way, 1685 genes were predicted for miR-320a, 1697 genes were predicted for miR-320b and 1417 genes were predicted for miR-320c. Interestingly, 73\% $(1319 / 1801$; Figure 6$)$ of the genes were predicted for all three miRNAs, $91.5 \%$ (1648/1801) were predicted for both miR-320a/-b, 74\% (1327/1801) were predicted for both miR-320a/-c and 74.5\% (1342/1801) were predicted for both miR-320b/-c. Only $1.6 \%, 1.4 \%$ and $3.7 \%$ were

A

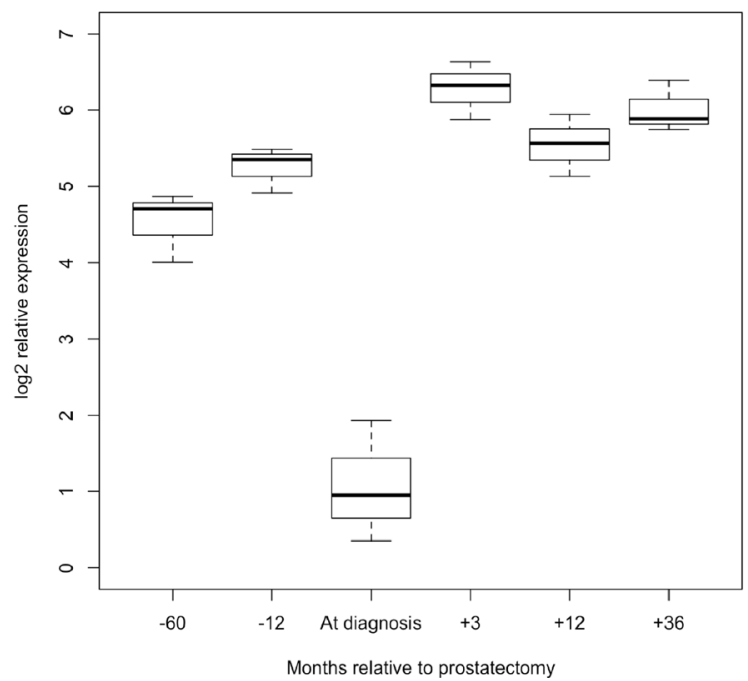

single target genes for miR-320a, -b and -c, respectively (Figure 6). To further elucidate the main pathways targeted by these miRNA target genes, we performed pathway enrichment analysis.

\section{Pathway enrichment analysis}

For pathway enrichment analysis, three different programs were used: WIKI pathways, KEGG and REACTOME. We considered only pathways that were predicted to be significantly affected (adjusted $p$-value, $P \leq 0.05$ ). Based on the results from the miRTarBase (high confidence target genes), several cancer pathways were identified using WIKI pathways and KEGG (Supplementary Table 1, marked in orange); the prostate cancer pathway was identified in KEGG (hsa05215; Supplementary Table 1, marked in yellow). Of note, the second most significantly enriched pathway extracted in KEGG with the high confidence target genes (second to the axon guidance pathway) was the PI3K-Akt signaling pathway (marked in ochre), which is one of the most affected pathways in prostate cancer [22]. Using putative miRNA targets obtained from miRWalk2.0, we also identified several cancer pathways in the three programs, including the prostate cancer pathway (hsa05215) in KEGG (Supplementary Table 1, marked in orange and in yellow).

\section{DISCUSSION}

To study miR-320 family members and their association with clinico-pathological parameters as well

B

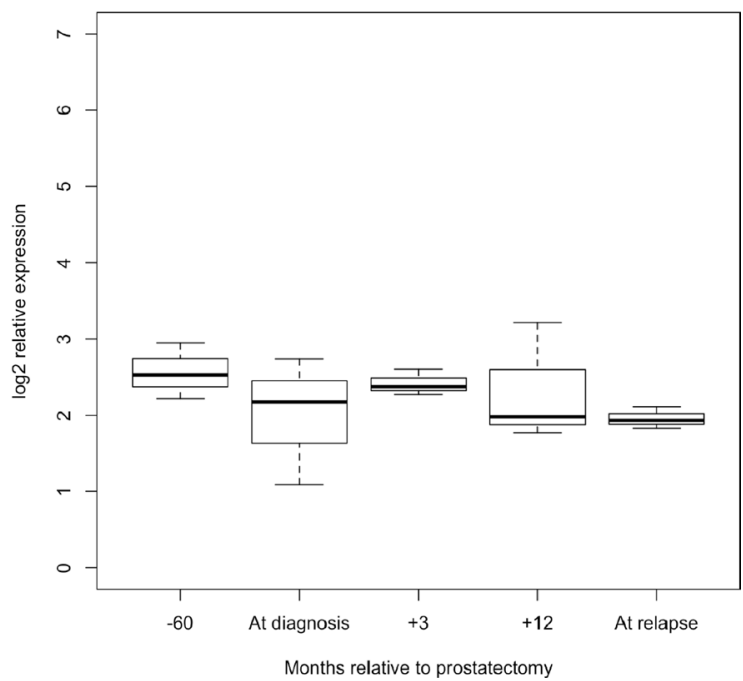

Figure 3: Progression profile of the levels of the miR-320 family members in the serum of PCa patients with/without PSA relapse (Innsbruck cohort). Serum samples (each pooled from 5 or 4 patients) obtained 5 years and one year before PCa diagnosis, at diagnosis, and 3 months, 1 year and 3 years after diagnosis were analyzed for the levels of miR-320a, -b, and -c in PCa patients without (A) and with PSA relapse (B). A strong decrease in all three miR-320 family members at the time of diagnosis was observed in PCa patients without PSA relapse but not in those with PSA relapse. 
A

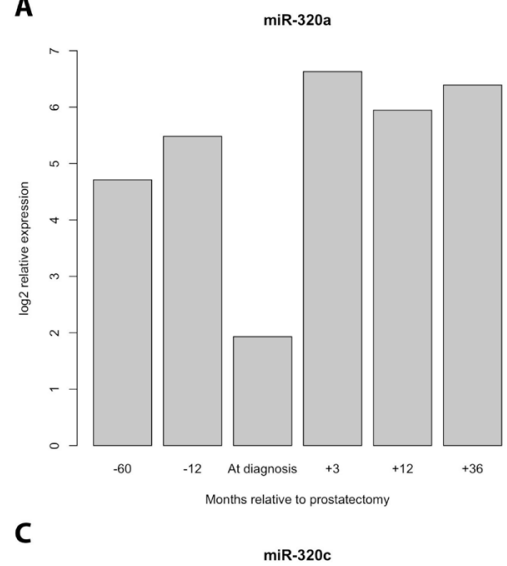

C

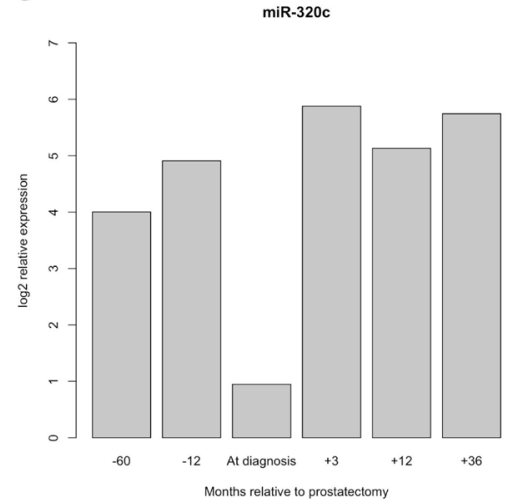

D

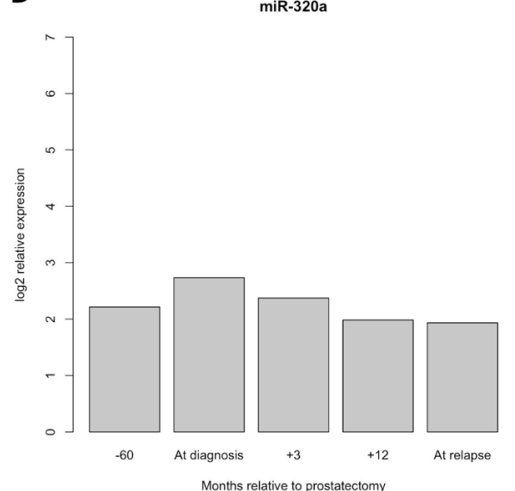

$\mathbf{F}$

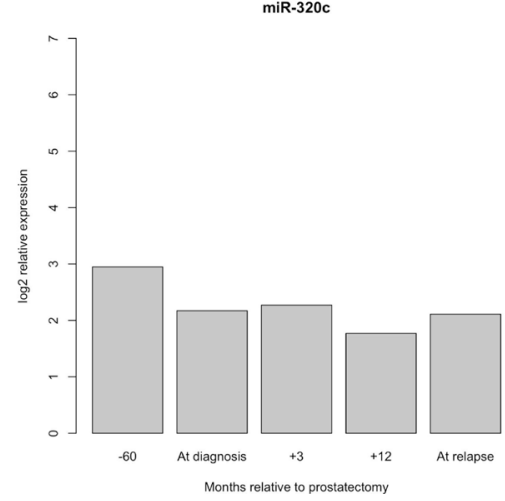

B

miR-320b

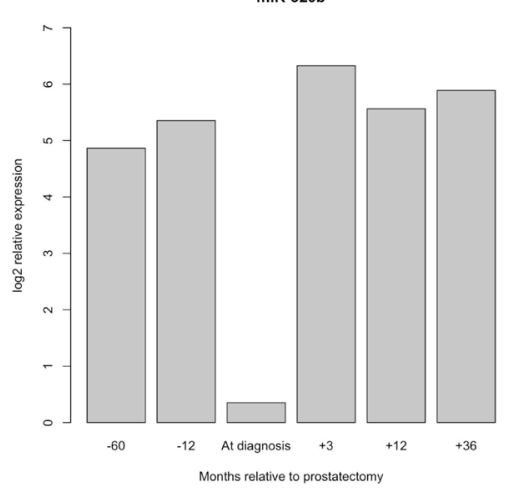

E

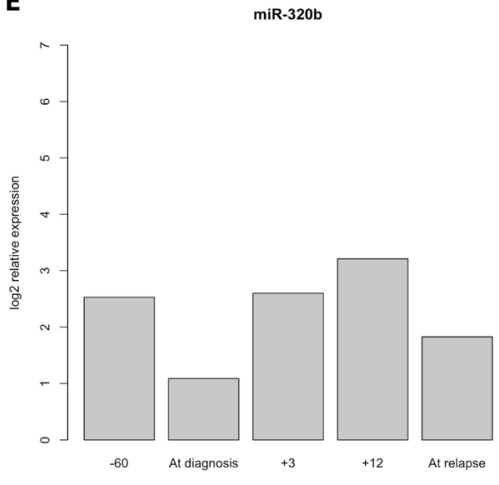

Figure 4: Detailed progression profile of the levels of the miR-320 family members for PCa patients without and with PSA relapse. PCa patients without PSA relapse (A-C) All three miRNAs showed relatively high levels at 5 years and at 1 year before the diagnosis of PCa but a strong decrease at the time of PCa diagnosis. Remarkably, the previous high levels of miRNA-320 a, -b and -c were already reached three months after diagnosis and were maintained in PCa patients without PSA relapse. PCa patients with PSA relapse (D-F). 
as their diagnostic and prognostic utility, we analyzed serum samples obtained from liquid biopsies. The rationale for liquid biopsy is that tumors shed cells and/or genetic fragments, such as CTCs (circulating tumor cells) or cell-free nucleic acids (including miRNAs), into the circulation, which makes the blood/serum representative of PCa [23-26]. The levels of miR-320a/-b/-c in serum samples from patients with $\mathrm{PCa}$, patients with benign prostatic hyperplasia $(\mathrm{BPH})$ and healthy controls were significantly different, which suggests that all three miRNAs may serve as diagnostic biomarkers. In patients with PCa, a direct association was observed between an increased level of all three miR-320 family members and the age of these patients, but this was not the case for the patients with BPH or the healthy controls. Furthermore, the levels of all three miR-320 family members were directly associated with tumor stage but were inversely correlated with the level of PSA in the serum. Since a rising PSA level is a marker of $\mathrm{PCa}$ recurrence, we sought to determine if miR-320 levels are different between patients with/without $\mathrm{PCa}$ recurrence. PCa patients without a PSA relapse had significantly lower levels of all three miRNAs at the time of diagnosis compared with the pre-diagnosis or post-RPE time points, whereas $\mathrm{PCa}$ patients with a later PSA relapse showed a measurable decrease in the level of miR-320b at the time of diagnosis. In contrast, patients who underwent prostatectomy and who did not experience PSA relapse exhibited high levels of miR-320 a, b and -c after surgery, and PCa patients with relapse exhibited comparably lower levels of all three miRNAs. Altogether, miR-320a, -b and -c may serve as diagnostic biomarkers i) to distinguish PCa patients from those with $\mathrm{BPH}$ and from healthy controls, ii) to identify PCa patients early and iii) to identify those with a PSA relapse.

The low miR-320 levels measured in the serum at the time of $\mathrm{PCa}$ diagnosis are in agreement with the reported downregulation of miR-320 in prostate tumor tissue $[14,15]$. With this in mind, we searched for miR-320 targets and possible functional consequences of miR-320 alterations. miR-320 (mostly miR-320a-3p) is considered to be a tumor suppressor miRNA, and several of its target genes/proteins that are involved in different physiological and tumor pathways (e.g., ß-catenin, Myc, STAT3) have been reported (Supplementary Tables 1 and 2).

The miRwalk program in silico also identified the androgen receptor (AR) as a direct target gene/ protein of miR-320a, -b, and -c (Supplementary Table 1). This was recently confirmed by Sato and colleagues who identified the binding (seed) sequence of miR-

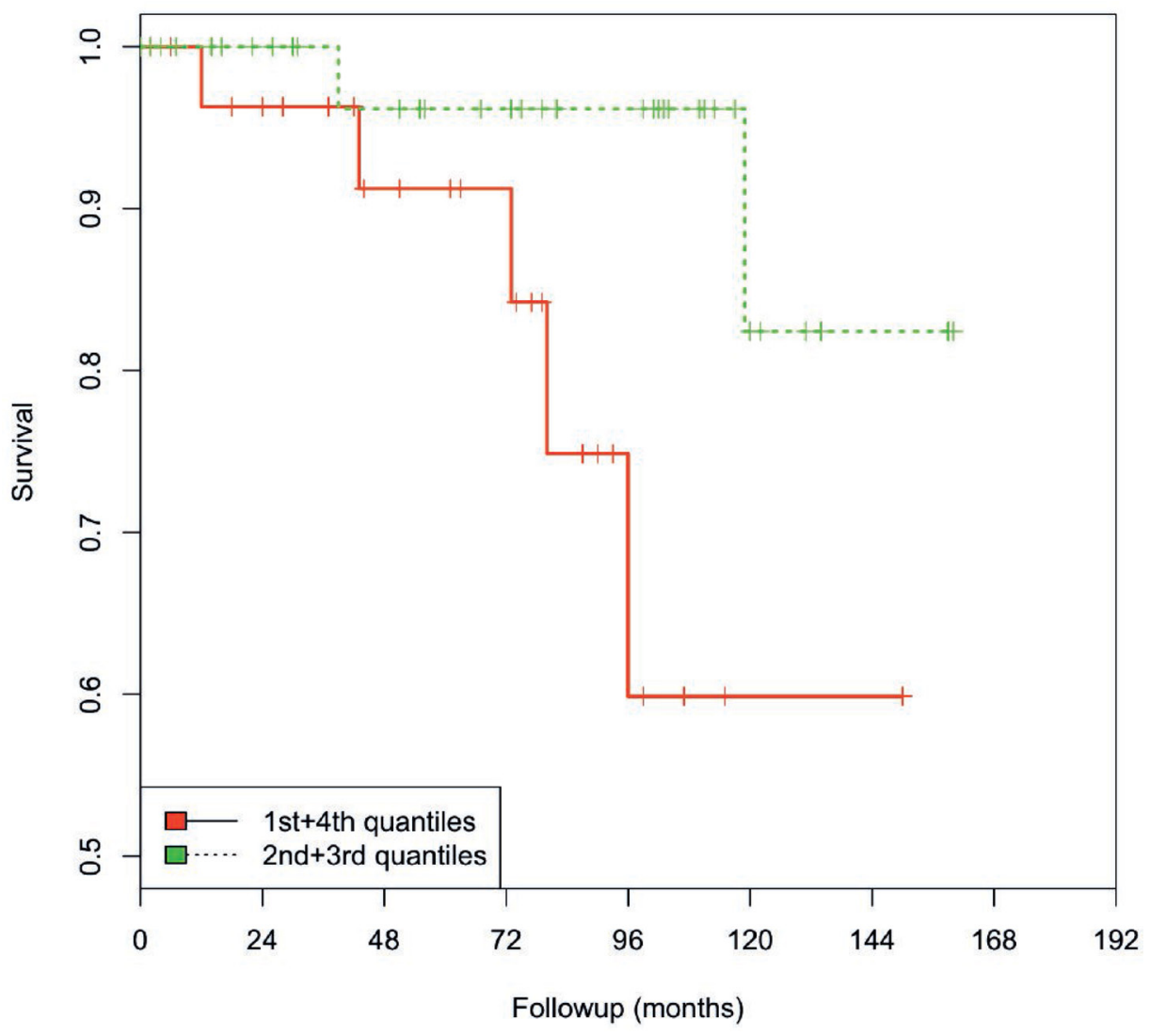

Figure 5: Kaplan-Meier analysis. The levels of miR-320b in group 1 (1st and 4th quartiles/red line) compared with group 2 (2nd and 3rd quartiles/green line) were associated with OS in younger PCa patients ( $\leq 66$ years). PCa patients with a low/high miR-320b level survived only 119 months compared with the patients with an intermediate miR-320b level (mean: 149 months; $P=0.034$; log-rank test). 
320a (3'-GUCGAAA-5') to AR, which is also present in $\mathrm{miR}-320 \mathrm{~b}$ and $-\mathrm{c}$; this suggests that all three family members regulate the expression of AR. In addition, the transcription factor SP1, which activates the transcription of AR [27], is also an in silico target of miR-320a, -b and -c (Supplementary Table 1). The downregulation of AR by miR-320a, -b and -c would result in decreased transcription of the AR target PSA, which would explain the inverse correlation of PSA and miR-320 levels.

Sato and colleagues also reported that a low miR320a level was associated with poor OS [15]. After an examination of the correlation of miR-320a, -b, and -c levels with OS in this study, only a relationship between a low/high level (1st and 4th quartiles) of miR-320b, as opposed to intermediate levels (2nd and 3rd quartiles), and a poorer OS in younger PCa patients ( $\leq 66$ years) was observed. The surprising finding that both a high and a low level are associated with a poorer prognosis suggests that both a reduction and an increase in miR$320 \mathrm{~b}$ can support tumor development. It was proposed that miRNA-320b may compete with miRNA-320a, which would therefore up-regulate the target genes of miRNA320a including $\beta$-catenin, Neuropilin- 1 and Rac- 1 . These genes are all known as promoters of tumor proliferation, invasion and metastasis in colorectal cancer [28]; reviewed in Supplementary Tables 1 and 2. This remarkable mechanism exemplifies the control of tumor promotion pathways via homologous competition between miRNAs of the same family.

Since we observed an association only between the level of miR-320b and prognosis, we were interested in the commonalities and the differences in the miR-320 family members with respect to their proposed target genes. After the application of miRwalk, we found that $73 \%(1319 / 1801)$ of the genes predicted by at least five prediction programs were shared by miR-320a/-b and -c (Figure 6). However, miR-320b also has 26 predicted target genes that are not shared by the other two members (Figure 6). Of these, six genes (MANEA, MAPK9, NKAIN1, NUMB, SCL14L1, and SMC6) have been reported in PubMed to play a role in prostate cancer (https://www.ncbi.nlm.nih.gov/pubmed). MANEA has been described as an androgen responsive gene [29]. Expression of the MAPK9 gene is higher in metastatic prostate tumors than in primary prostate tumors [30]. Expression of the NKAIN1 gene is higher in the urinary sediment of PCa patients than in normal controls, and among PCa patients, NKAIN1 expression is higher in

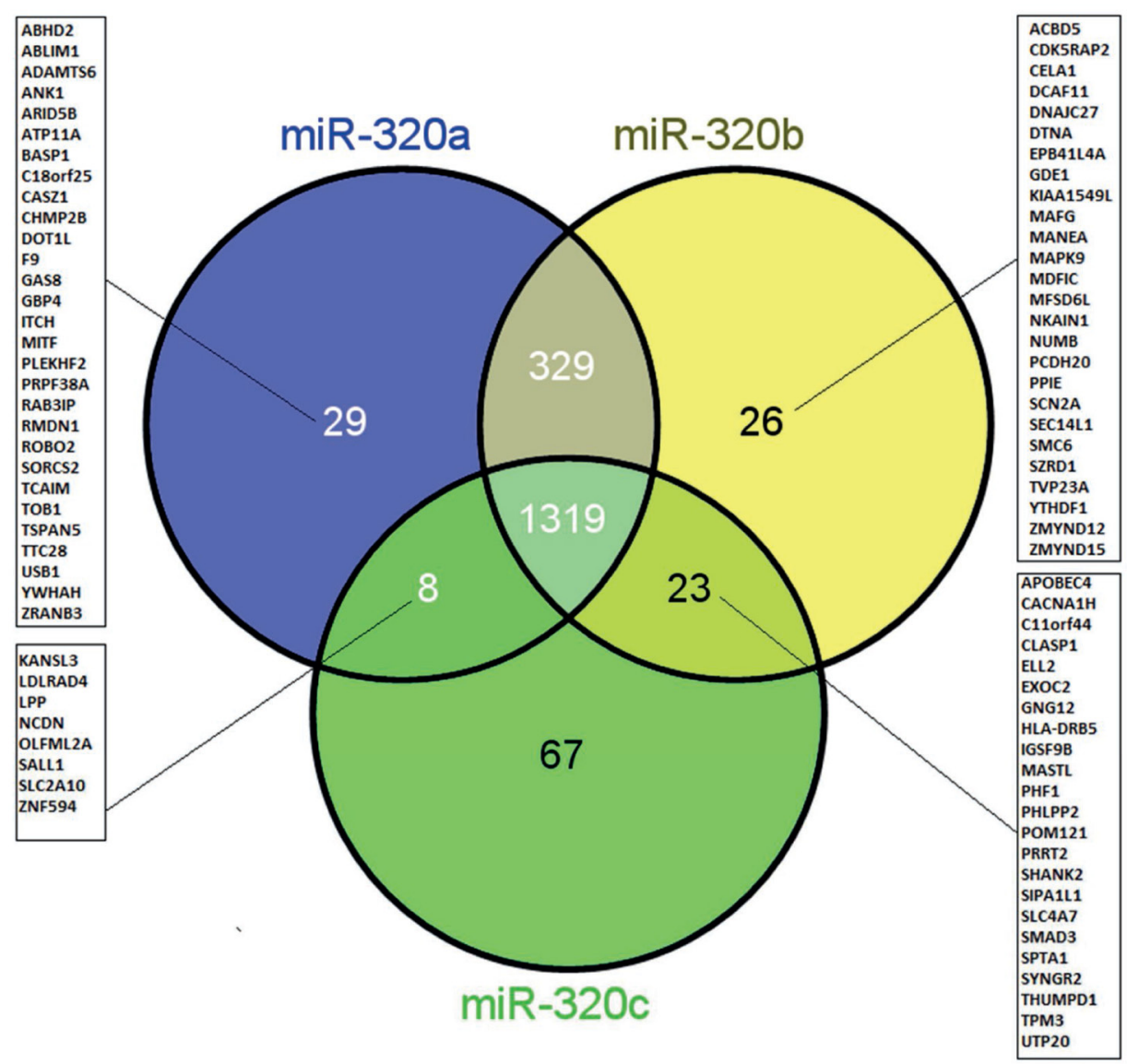

Figure 6: Venn diagram showing the overlap and singularity of predicted target genes of miR-320a, -b and -c. The miRNA target genes were predicted using the database miRwalk2.0. A strong overlap of target genes (73\%: 1319/1801) was observed for all three miRNAs. 
patients with Gleason scores $\geq 7$ than in patients with Gleason scores $\leq 6$, which suggests its utility as an early diagnostic marker of PCa [31]. NUMB (protein numb homologue) is a key regulator of cell fate that controls $\mathrm{NOTCH}$ and GLI, which play major roles in prostate cancer [32]. SCL14L1 expression has been associated with a high combined Gleason score, advanced tumor stage, and PSA progression, and therefore, may be used as a biomarker of progression in $\mathrm{PCa}$ [33]. Increased expression of the SMC6 gene after irradiation is associated with DNA damage and repair and has been reported in PCa patients [34]. However, until now, none of these miR$320 \mathrm{~b}$ predicted target genes/proteins have been confirmed by high-evidence methods. Altogether, we suggest that combination of several miRNA levels (including miR-320 family members and miR-141) can help to improve the accuracy of future risk models for PCa recurrence. But of course our results should be checked in larger, independent and prospective patient cohorts.

In summary, we showed that the levels of miR$320 \mathrm{a},-\mathrm{b}$ and $-\mathrm{c}$ are associated with each other within the different groups of PCa patients, BPH patients and healthy controls but that the levels differ significantly among these groups. The serum levels of all three miR-320 family members are significantly different in patients with low-stage tumors compared with those with advancedstage tumors $(\mathrm{pT} 1+\mathrm{pT} 2$ vs. pT3 + pT4 $)$ and are directly correlated to $\mathrm{pT}$ and indirectly correlated to PSA serum levels. PCa patients without tumor recurrence (PSA relapse) have higher levels of miR-320a/-b/-c before and after radical prostatectomy compared with patients with $\mathrm{PCa}$ recurrence. In addition, miR-320b levels (lowest and highest quartiles) were found to be associated with poor OS in younger PCa patients ( $\leq 66$ years). The prediction of miR-320a, -b, and -c target genes reveals a great overlap of potential target genes of all three miRNAs, and pathway enrichment analysis detected several cancer-related pathways. Altogether, the differences between the $\mathrm{PCa} /$ $\mathrm{BPH} /$ healthy control groups with respect to miR-320a/$\mathrm{b} /$-c levels in conjunction with higher levels in patients without a PCa relapse suggest the diagnostic utility of these miRNA-320 family members in PCa patients.

\section{MATERIALS AND METHODS}

\section{Clinical samples}

The miRNA levels of miR-320a, -b and c were analyzed in the serum of 145 non-selected patients with $\mathrm{PCa}$ (Halle cohort), 31 patients with BPH and 19 healthy controls. All of the patients were treated at the Department of Urology at Martin-Luther-University Halle-Wittenberg from 1995-2005. Blood samples were collected during routine diagnostic examinations. All patients provided written informed consent. To study the miR-320a, -b, and -c levels in PCa patients with or without PSA relapse, a second $\mathrm{PCa}$ cohort (Innsbruck cohort) from the PCa early detection program in Tyrol, Austria was analyzed [35]. The group of PCa patients with PSA relapse consisted of five patients while the group without PSA relapse consisted of four patients. Serum samples from both groups were assessed by microRNA microarrays to determine the levels of miR-320a, -b and -c. In the group of patients without recurrence, serum samples were obtained at 5 years and at 1 year before the diagnosis of $\mathrm{PCa}$, at diagnosis, and at approximately 3 months, 1 year and 3 years after radical prostatectomy (RPE). In the group of patients with recurrence, serum samples were available at 5-6 years before diagnosis, at diagnosis, and at approximately 3 months and 1 year after RPE, and at relapse. This study was performed in compliance with the Declaration of Helsinki. The use of blood samples for research was approved by the Internal Review Boards of the Medical Faculty of the Martin-Luther-University Halle-Wittenberg and the Ethics Committee of the Medical University Innsbruck. The tumors were staged according to the Union for International Cancer Control system, and they were graded according to the Gleason score system. The relevant clinico-pathological parameters of the $\mathrm{PCa}$ patient cohorts are presented in Table 3A and 3B.

\section{miRNA quantitative real-time PCR}

Serum miRNAs were purified using a miRCURY RNA isolation kit for body fluids (Exiqon, Vedbaek, Denmark). For the miRNA analysis, isolated RNA corresponding to $25 \mu \mathrm{l}$ of serum was reverse transcribed using a universal cDNA synthesis kit (Exiqon). Real-time PCR was performed with the StepOnePlus Real-Time PCR System (Life Technologies, Darmstadt, Germany) using sequence-specific primers for $\mathrm{miR}-320 \mathrm{a} / \mathrm{b} / \mathrm{c}$ and miR-141 (Exiqon). The PCR reactions were performed in triplicate in a final volume of $10 \mu$ containing $1 \times$ SYBR green PCR Master Mix, 1x sequence-specific primer mix, and cDNA, which corresponded to a miRNA amount of 5 $\mu 1$ serum per real-time PCR reaction. The thermal cycling conditions were selected according to the manufacturer's recommendations. To quantify the levels of miR-320a/b/c in the serum, we used the relative quantification $(\Delta \Delta \mathrm{Ct})$ method [36] and used miR-16-5p and miR425-5p as internal controls. All calculations were performed with the StepOne software V 2.0 (Life Technologies).

\section{miRNA differential expression analysis using microarrays}

The miRNA microarray expression analyses were performed on GeneChip miRNA 4.0 microarrays (Affymetrix, Santa Clara, CA, USA) according to the manufacturer's instructions. The array contained sequence-specific probes for 2,578 human mature miRNAs and 2,025 human pre-miRNAs listed in miRBase 
Table 3A: Clinico-pathological data of the PCa cancer patients from the Halle cohort

\begin{tabular}{|c|c|c|c|}
\hline & PCa & ВPH & healthy controls \\
\hline$N$ & 145 & 31 & 19 \\
\hline \multicolumn{4}{|l|}{ Age } \\
\hline range & $44-91$ & $55-89$ & $40-57$ \\
\hline mean & 65.7 & 70.4 & 46.4 \\
\hline median & 66.0 & 70.0 & 45.0 \\
\hline \multicolumn{4}{|l|}{ Gleason sum } \\
\hline$<7$ & 40 & n.a. & n.a. \\
\hline$=7$ & 54 & n.a. & n.a. \\
\hline$>7$ & 41 & n.a. & n.a. \\
\hline unknown & 10 & n.a. & n.a. \\
\hline \multicolumn{4}{|l|}{ Tumor stage } \\
\hline $\mathrm{T} 1 / 2$ & 98 & n.a. & n.a. \\
\hline $\mathrm{T} 3 / 4$ & 44 & n.a. & n.a. \\
\hline unknown & 3 & n.a. & n.a. \\
\hline \multicolumn{4}{|l|}{ PSA } \\
\hline$<4$ ng & 45 & n.a. & n.a. \\
\hline$\geq 4 \mathrm{ng}$ & 100 & n.a. & n.a. \\
\hline \multicolumn{4}{|l|}{ Overall survival } \\
\hline alive & 115 & 31 & 19 \\
\hline dead & 30 & 0 & 0 \\
\hline \multicolumn{4}{|c|}{ Disease-specific survival } \\
\hline alive & 135 & 31 & 19 \\
\hline dead & 10 & 0 & 0 \\
\hline
\end{tabular}

n.a.-not applicable.

Table 3B: Clinico-pathological data of the PCa patients from the Innsbruck cohort

\begin{tabular}{|c|c|c|c|c|c|c|c|}
\hline PCa Patients & ID & age & $\begin{array}{l}\text { PSA at biopsy } \\
\text { (Diagnosis) }\end{array}$ & $\begin{array}{l}\text { GS at } \\
\text { biopsy }\end{array}$ & $\begin{array}{l}\text { GS at } \\
\text { RPE }\end{array}$ & $\mathbf{p T}$ & $\begin{array}{c}\text { time between } \mathrm{RPE} \\
\text { and PSA relapse (in days) }\end{array}$ \\
\hline \multicolumn{8}{|c|}{ Without progression } \\
\hline & wo1 & 58 & 2.8 & 6 & 5 & $2 b$ & n.a. \\
\hline & wo2 & 63 & 6.0 & 7 & 8 & $2 \mathrm{c}$ & n.a. \\
\hline & wo3 & 78 & n.d. & 6 & 6 & $2 \mathrm{c}$ & n.a. \\
\hline & wo4 & 71 & 6.19 & 6 & 7 & $2 c$ & n.a. \\
\hline & wo5 & 68 & 2.96 & 6 & 7 & $2 \mathrm{c}$ & n.a. \\
\hline \multicolumn{8}{|c|}{ With progression } \\
\hline & w1 & 64 & 2.03 & 8 & 7 & $3 a$ & 841 \\
\hline & w2 & 66 & 4.96 & 7 & 7 & $3 b$ & 1263 \\
\hline & w3 & 63 & 9.0 & 5 & 7 & $2 \mathrm{c}$ & 1114 \\
\hline & w4 & 61 & 1.97 & 7 & 9 & $2 c$ & 1653 \\
\hline
\end{tabular}

n.d.-not determined, n.a.-not applicable. 
v20.0 (http://www.mirbase.org). The resulting data were further analyzed with Partek Genomics Suite software v6.6 (Partek, St Louis, MO, USA). To identify miRNAs differentially expressed between the defined sample groups, ANOVA test statistics were applied.

\section{miRNA target genes}

We used miRTarBase 2016 (release 6.0) to identify experimentally verified miRNA targets [37]. Those targets that were verified by reliable technologies (e.g., qPCR, western blot and reporter assays) were chosen for pathway enrichment analyses. The miRwalk2.0 database was used to identify the target genes of the identified deregulated miRNAs [38]. The putative miRNA target genes predicted by five independent algorithms, including miRwalk (v2.0), DIANA-microT (v4.0), MiRanda (released in 2010), RNA22 (v2) and Targetscan (v6.1), were extracted for the subsequent analyses. This allows a reduction in the number of false-positive results, which is a common issue in existing miRNA target prediction programs [39].

\section{Pathway enrichment analyses}

We used the obtained miRNA target genes to perform pathway enrichment analyses. These gene lists were used as the inputs for the web-based platform Enrichr [40]. The outputs are lists of biological pathways/terms to which given miRNA target genes belong. The biological pathways/terms were derived from curated databases such as KEGG [41], WIKIPathways [42] and Reactome [43]. Fisher's exact test was employed to determine the significance of a biological pathway/term to the given gene lists. The pathways/terms with corrected $p$-values $\leq$ 0.05 (adjusted using the Benjamini-Hochberg procedure) were regarded as significant.

\section{Statistical analysis}

According to the exact time point of blood collection, the PCa patients were classified into one of the following three groups: (1) patients who did not undergo radical prostatectomy and who were diagnosed with $\mathrm{PCa}$ based solely on biopsy specimens, (2) patients whose blood was collected before radical prostatectomy, and (3) patients whose blood was collected at least six months after radical prostatectomy in order to exclude postsurgery effects on the miR-320 levels. The distribution of miR-320a, -b, and -c did not differ among the three defined groups (data not shown), and therefore, we did not further distinguish among them in this study. Correlations between continuous variables of the biological markers were calculated by Spearman's rank correlation test $\left(\mathrm{r}_{\mathrm{s}}\right)$. For further statistical analysis, expression levels were separated into four groups according to the $25 \%, 50 \%$ and $75 \%$ percentiles $(\leq 25 \%,>25 \%$ to $\leq 50 \%,>50 \%$ to $\leq 75 \%$ and $>75 \%$ ). The differences among the levels of miR-
$320 \mathrm{a},-\mathrm{b}$, and $-\mathrm{c}$ in the serum of patients with $\mathrm{PCa}$ and $\mathrm{BPH}$ and healthy volunteers were estimated using the MannWhitney $U$-test and the Kruskal Wallis test. For survival analyses in patients with $\mathrm{PCa}$, OS was defined as the time from diagnosis to death, which was used as the follow-up end point. Statistical analyses of the association between miR-320a, -b, and -c levels and prognosis were performed according to the Kaplan-Meier method (log-rank test) and multivariate Cox's proportional hazard regression models. The multivariate Cox's regression hazard model was adjusted to PSA level and tumor stage. All calculations were performed using the SPSS 20.0 statistical package (SPSS-Science, Chicago, IL, USA) and R Ver. 3.2.1 (R Foundation for Statistical Computing, Vienna, Austria. http://www.R-project.org/).

\section{Author contributions}

S.W., H.T. and V.L. conceived and designed the study. S.W., K.W. and L.S. performed all experiments with help from A.B.E. and S.L. and, A.B.E. analyzed the microarray data, and X.L. and J.V. performed the pathway enrichment analyses. S.W., X.L. and H.T. prepared the figures. S.W., H.T., T.G., K.F., M.M. G.T., W.H., H.K. and H.-J.H. interpreted and discussed the data with all authors. S.W., H.T., V.L and X.L. wrote the manuscript in conjunction with J.V., P.F. and B.W. All authors contributed to the preparation of the final manuscript and reviewed the submitted manuscript.

\section{ACKNOWLEDGMENTS AND FUNDING}

We are very thankful for the financial support of a grant from the Förderverein Hilfe beim Prostatakrebs e.V./Movember (S.W., H.T.) and a grant from Johannes und Frieda Marohn-Stiftung (S.W). X.L. and J.V. were supported by the German Federal Ministry of Education and Research (BMBF) project e:Bio MelEVIR (031L0073A). In addition, we thank American Journal Experts for editing the manuscript.

\section{CONFLICTS OF INTEREST}

All authors declare to have no conflicts of interest.

\section{REFERENCES}

1. Tao L, Bei Y, Zhou Y, Xiao J, Li X. Non-coding RNAs in cardiac regeneration. Oncotarget. 2015; 6:42613-22. https:// doi.org/10.18632/oncotarget.6073.

2. Feng B, Chakrabarti S. miR-320 Regulates GlucoseInduced Gene Expression in Diabetes. ISRN Endocrinol. 2012; 2012:549875. https://doi.org/10.5402/2012/549875.

3. Yan LX, Huang XF, Shao Q, Huang MY, Deng L, Wu QL, Zeng YX, Shao JY. MicroRNA miR-21 overexpression in 
human breast cancer is associated with advanced clinical stage, lymph node metastasis and patient poor prognosis. RNA. 2008; 14:2348-60. https://doi.org/10.1261/ rna.1034808.

4. Bronisz A, Godlewski J, Wallace JA, Merchant AS, Nowicki MO, Mathsyaraja H, Srinivasan R, Trimboli AJ, Martin CK, Li F, Yu L, Fernandez SA, Pecot T, et al. Reprogramming of the tumour microenvironment by stromal PTEN-regulated miR-320. Nat Cell Biol. 2011; 14:159-67. https://doi. org/10.1038/ncb2396.

5. Blenkiron C, Hurley DG, Fitzgerald S, Print CG, Lasham A. Links between the oncoprotein YB-1 and small non-coding RNAs in breast cancer. PLoS One. 2013; 8:e80171. https:// doi.org/10.1371/journal.pone.0080171.

6. Ak G, Tomaszek SC, Kosari F, Metintas M, Jett JR, Metintas S, Yildirim H, Dundar E, Dong J, Aubry MC, Wigle DA, Thomas CF Jr. MicroRNA and mRNA features of malignant pleural mesothelioma and benign asbestosrelated pleural effusion. Biomed Res Int. 2015; 2015: 635748. https://doi.org/10.1155/2015/635748.

7. Chen L, Yan HX, Yang W, Hu L, Yu LX, Liu Q, Li L, Huang DD, Ding J, Shen F, Zhou WP, Wu MC, Wang HY. The role of microRNA expression pattern in human intrahepatic cholangiocarcinoma. J Hepatol. 2009; 50:358-69. https:// doi.org/10.1016/j.jhep.2008.09.015.

8. Yao J, Liang LH, Zhang Y, Ding J, Tian Q, Li JJ, He XH. GNAI1 Suppresses Tumor Cell Migration and Invasion and is Post-Transcriptionally Regulated by Mir-320a/c/d in Hepatocellular Carcinoma. Cancer Biol Med. 2012; 9:234- 41. https://doi.org/10.7497/j.issn.2095-3941.2012.04.003.

9. Lei $\mathrm{T}$, Zhu Y, Jiang $\mathrm{C}$, Wang $\mathrm{Y}, \mathrm{Fu}$ J, Fan Z, Qin H. MicroRNA-320 was downregulated in non-small cell lung cancer and inhibited cell proliferation, migration and invasion by targeting fatty acid synthase. Mol Med Rep. 2016; 14:1255-62. https://doi.org/10.3892/mmr.2016.5370.

10. Gao W, Shen H, Liu L, Xu J, Xu J, Shu Y. MiR-21 overexpression in human primary squamous cell lung carcinoma is associated with poor patient prognosis. J Cancer Res Clin Oncol. 2011; 137:557-66. https://doi. org/10.1007/s00432-010-0918-4.

11. Schepeler T, Reinert JT, Ostenfeld MS, Christensen LL, Silahtaroglu AN, Dyrskjot L, Wiuf C, Sorensen FJ, Kruhoffer M, Laurberg S, Kauppinen S, Orntoft TF, Andersen CL. Diagnostic and prognostic microRNAs in stage II colon cancer. Cancer Res. 2008; 68:6416-24. https://doi.org/10.1158/0008-5472.CAN-07-6110.

12. Gattolliat $\mathrm{CH}$, Uguen A, Pesson M, Trillet K, Simon B, Doucet L, Robaszkiewicz M, Corcos L. MicroRNA and targeted mRNA expression profiling analysis in human colorectal adenomas and adenocarcinomas. Eur J Cancer. 2015; 51:409-20. https://doi.org/10.1016/j. ejca.2014.12.007.

13. Goto Y, Kojima S, Nishikawa R, Kurozumi A, Kato M, Enokida H, Matsushita R, Yamazaki K, Ishida Y,
Nakagawa M, Naya Y, Ichikawa T, Seki N. MicroRNA expression signature of castration-resistant prostate cancer: the microRNA-221/222 cluster functions as a tumour suppressor and disease progression marker. Br J Cancer. 2015; 113:1055-65. https://doi.org/10.1038/bjc.2015.300.

14. Hsieh IS, Chang KC, Tsai YT, Ke JY, Lu PJ, Lee KH, Yeh SD, Hong TM, Chen YL. MicroRNA-320 suppresses the stem cell-like characteristics of prostate cancer cells by downregulating the Wnt/beta-catenin signaling pathway. Carcinogenesis. 2013; 34:530-8. https://doi.org/10.1093/ carcin/bgs371.

15. Sato S, Katsushima K, Shinjo K, Hatanaka A, Ohka F, Suzuki S, Naiki-Ito A, Soga N, Takahashi S, Kondo Y. Histone Deacetylase Inhibition in Prostate Cancer Triggers miR-320-Mediated Suppression of the Androgen Receptor. Cancer Res. 2016; 76:4192-204. https://doi. org/10.1158/0008-5472.CAN-15-3339.

16. Wu YY, Chen YL, Jao YC, Hsieh IS, Chang KC, Hong TM. miR-320 regulates tumor angiogenesis driven by vascular endothelial cells in oral cancer by silencing neuropilin 1 . Angiogenesis. 2014; 17:247-60. https://doi.org/10.1007/ s10456-013-9394-1.

17. Zhang T, Zou P, Wang T, Xiang J, Cheng J, Chen D, Zhou J. Down-regulation of miR-320 associated with cancer progression and cell apoptosis via targeting Mcl-1 in cervical cancer. Tumour Biol. 2016; 37:8931-40. https:// doi.org/10.1007/s13277-015-4771-6.

18. Zhao JJ, Yang J, Lin J, Yao N, Zhu Y, Zheng J, Xu J, Cheng JQ, Lin JY, Ma X. Identification of miRNAs associated with tumorigenesis of retinoblastoma by miRNA microarray analysis. Childs Nerv Syst. 2009; 25:13-20. https://doi. org/10.1007/s00381-008-0701-x.

19. Dong L, Li Y, Han C, Wang X, She L, Zhang H. miRNA microarray reveals specific expression in the peripheral blood of glioblastoma patients. Int J Oncol. 2014; 45:74656. https://doi.org/10.3892/ijo.2014.2459.

20. Watahiki A, Macfarlane RJ, Gleave ME, Crea F, Wang Y, Helgason CD, Chi KN. Plasma miRNAs as biomarkers to identify patients with castration-resistant metastatic prostate cancer. Int J Mol Sci. 2013; 14:7757-70. https:// doi.org/10.3390/ijms14047757.

21. Selth LA, Townley SL, Bert AG, Stricker PD, Sutherland PD, Horvath LG, Goodall GJ, Butler LM, Tilley WD. Circulating microRNAs predict biochemical recurrence in prostate cancer patients. Br J Cancer. 2013; 109:641-50. https://doi.org/10.1038/bjc.2013.369.

22. Toren P, Zoubeidi A. Targeting the PI3K/Akt pathway in prostate cancer: challenges and opportunities (review). Int J Oncol. 2014; 45:1793-801. https://doi.org/10.3892/ ijo.2014.2601.

23. Kuner R, Brase JC, Sultmann H, Wuttig D. microRNA biomarkers in body fluids of prostate cancer patients. Methods. 2013; 59:132-7. https://doi.org/10.1016/j. ymeth.2012.05.004. 
24. Dimakakos A, Armakolas A, Koutsilieris M. Novel tools for prostate cancer prognosis, diagnosis, and follow-up. Biomed Res Int. 2014; 2014:890697. https://doi. org $/ 10.1155 / 2014 / 890697$

25. Fang YX, Gao WQ. Roles of microRNAs during prostatic tumorigenesis and tumor progression. Oncogene. 2014; 33:135-47. https://doi.org/10.1038/onc.2013.54.

26. Valentino A, Reclusa P, Sirera R, Giallombardo M, Camps C, Pauwels P, Crispi S, Rolfo C. Exosomal microRNAs in liquid biopsies: future biomarkers for prostate cancer. Clin Transl Oncol. 2017; 19:651-57. https://doi.org/10.1007/ s12094-016-1599-5.

27. Hay CW, Hunter I, MacKenzie A, McEwan IJ. An Sp1 Modulated Regulatory Region Unique to Higher Primates Regulates Human Androgen Receptor Promoter Activity in Prostate Cancer Cells. PLoS One. 2015; 10: e0139990. https://doi.org/10.1371/journal.pone.0139990.28.

28. Zhou J, Zhang M, Huang Y, Feng L, Chen H, Hu Y, Chen $\mathrm{H}$, Zhang K, Zheng L, Zheng S. MicroRNA-320b promotes colorectal cancer proliferation and invasion by competing with its homologous microRNA-320a. Cancer Lett. 2015; 356:669-75. https://doi.org/10.1016/j.canlet.2014.10.014.

29. Romanuik TL, Wang G, Holt RA, Jones SJ, Marra MA, Sadar MD. Identification of novel androgen-responsive genes by sequencing of LongSAGE libraries. BMC Genomics. 2009; 10:476. https://doi.org/10.1186/1471-2164-10-476.

30. Tseng JC, Lin CY, Su LC, Fu HH, Yang SD, Chuu CP. CAPE suppresses migration and invasion of prostate cancer cells via activation of non-canonical Wnt signaling. Oncotarget. 2016; 7:38010-24. https://doi.org/10.18632/ oncotarget.9380.

31. Leyten GH, Hessels D, Smit FP, Jannink SA, de Jong H, Melchers WJ, Cornel EB, de Reijke TM, Vergunst H, Kil P, Knipscheer BC, Hulsbergen-van de Kaa CA, Mulders $\mathrm{PF}$, et al. Identification of a Candidate Gene Panel for the Early Diagnosis of Prostate Cancer. Clin Cancer Res. 2015; 21:3061-70. https://doi.org/10.1158/1078-0432. CCR-14-3334.

32. Flores AN, McDermott N, Meunier A, Marignol L. NUMB inhibition of NOTCH signalling as a therapeutic target in prostate cancer. Nat Rev Urol. 2014; 11:499-507. https:// doi.org/10.1038/nrurol.2014.195.

33. Agell L, Hernandez S, Nonell L, Lorenzo M, Puigdecanet E, de Muga S, Juanpere N, Bermudo R, Fernandez PL, Lorente JA, Serrano S, Lloreta J. A 12-gene expression signature is associated with aggressive histological in prostate cancer: SEC14L1 and TCEB1 genes are potential markers of progression. Am J Pathol. 2012; 181:1585-94. https://doi.org/10.1016/j.ajpath.2012.08.005.

34. El-Saghire H, Vandevoorde C, Ost P, Monsieurs P, Michaux A, De Meerleer G, Baatout S, Thierens H. Intensity modulated radiotherapy induces pro-inflammatory and prosurvival responses in prostate cancer patients. Int J Oncol. 2014; 44:1073-83. https://doi.org/10.3892/ijo.2014.2260.

35. Heidegger I, Fritz J, Klocker H, Pichler R, Bektic J, Horninger W. Age-Adjusted PSA Levels in Prostate Cancer Prediction: Updated Results of the Tyrol Prostate Cancer Early Detection Program. PLoS One. 2015; 10:e0134134. https://doi.org/10.1371/journal.pone.0134134.

36. Schmittgen TD, Livak KJ. Analyzing real-time PCR data by the comparative C(T) method. Nat Protoc. 2008; 3:1101-8.

37. Chou CH, Chang NW, Shrestha S, Hsu SD, Lin YL, Lee WH, Yang CD, Hong HC, Wei TY, Tu SJ, Tsai TR, Ho SY, Jian TY, et al. miRTarBase 2016: updates to the experimentally validated miRNA-target interactions database. Nucleic Acids Res. 2016; 44:D239-47. https:// doi.org/10.1093/nar/gkv1258.

38. Dweep H, Gretz N. miRWalk2.0: a comprehensive atlas of microRNA-target interactions. Nat Methods. 2015; 12:697. https://doi.org/10.1038/nmeth.3485.

39. Pinzon N, Li B, Martinez L, Sergeeva A, Presumey J, Apparailly F, Seitz H. microRNA target prediction programs predict many false positives. Genome Res. 2017; 27:234-45. https://doi.org/10.1101/gr.205146.116.

40. Chen EY, Tan CM, Kou Y, Duan Q, Wang Z, Meirelles GV, Clark NR, Ma'ayan A. Enrichr: interactive and collaborative HTML5 gene list enrichment analysis tool. BMC Bioinformatics. 2013; 14:128. https://doi. org/10.1186/1471-2105-14-128.

41. Kanehisa M, Sato Y, Kawashima M, Furumichi M, Tanabe M. KEGG as a reference resource for gene and protein annotation. Nucleic Acids Res. 2016; 44:D457-62. https:// doi.org/10.1093/nar/gkv1070.

42. Kutmon M, Riutta A, Nunes N, Hanspers K, Willighagen EL, Bohler A, Melius J, Waagmeester A, Sinha SR, Miller R, Coort SL, Cirillo E, Smeets B, et al. WikiPathways: capturing the full diversity of pathway knowledge. Nucleic Acids Res. 2016; 44: D488-94. https://doi.org/10.1093/nar/gkv1024.

43. Fabregat A, Sidiropoulos K, Garapati P, Gillespie M, Hausmann K, Haw R, Jassal B, Jupe S, Korninger F, McKay S, Matthews L, May B, Milacic M, et al. The Reactome pathway Knowledgebase. Nucleic Acids Res. 2016; 44:D481-7. https://doi.org/10.1093/nar/gkv1351. 